\title{
Partial posteromedial papillary muscle rupture as an early complication after acute inferior ST-elevation myocardial infarction treated with primary percutaneous intervention
}

\author{
Ewa Szymczyk ${ }^{1}$, Grzegorz Religa ${ }^{2}$, Tomasz Kaszczyński², Paulina Wejner-Mik ${ }^{1}$, Piotr Lipiec ${ }^{1}$, \\ Jarosław D. Kasprzak ${ }^{1}$ \\ ${ }^{1}$ Department of Cardiology, Medical University of Lodz, Bieganski Hospital, Lodz, Poland \\ ${ }^{2}$ Department of Cardiac Surgery, Bieganski Hospital, Lodz, Poland
}

Adv Interv Cardiol 2017; 13, 2 (48): 176-177 DOI: https://doi.org/10.5114/pwki.2017.67995

In the era of primary percutaneous coronary interventions papillary muscle rupture is a rare complication of myocardial infarction and usually presents with acute pulmonary edema and cardiogenic shock [1, 2]. We illustrate the less common scenario of partial papillary muscle rupture which did not initially present as emergency despite severe acute mitral regurgitation but subsequently progressed to acute heart failure [3]. This case report also underlines the importance of expert physical examination for early recognition of papillary muscle rupture, so that life-saving treatment can be administered without delay.

A 62-year-old, previously healthy man with first in his life retrosternal chest pain of $2 \mathrm{~h}$ duration was admitted to the department of cardiology. On ECG ST-segment elevations were present in inferior leads. Acute inferior ST-elevation myocardial infarction was diagnosed and coronary angiography revealed critical right coronary stenosis (Figure $1 \mathrm{C}$ ). After balloon predilatation two drug-eluting stents (Resolute $3.5 \times 18 \mathrm{~mm}$ and $3.5 \times$ $26 \mathrm{~mm}$ ) were implanted in the right coronary artery resulting in TIMI III flow. After the procedure retrosternal chest pain diminished and the condition of the patient was stable. During routine follow-up physical examination on the doctor's round $2 \mathrm{~h}$ later, a new 2/6 systolic murmur was heard in the apex, suggestive for mechanical complication. Ad hoc transthoracic echocardiography revealed a significant eccentric jet of mitral regurgitation in color Doppler, with high mitral inflow velocity $(1.3 \mathrm{~m} / \mathrm{s})$ without left atrium enlargement. Partial disruption of the posteromedial papillary muscle resulting in partial flail of the posterior mitral leaflet with concomitant severe mitral regurgitation was diagnosed (Figures $1 \mathrm{~A}$ and $\mathrm{B}$ ). Moderate wall motion abnormalities from the territory of the right coronary artery were visualized with left ventricular ejection fraction (LVEF) of $45 \%$. The patient was immediately referred to the cardiac surgery department and during routine preparation for cardiac surgery his condition deteriorated with the presentation of pulmonary edema. Cardiopulmonary bypass was instituted and surgery was performed at normothermia under cold blood cardioplegia. The inspection confirmed echocardiographic data. Visible damage to the residual part of the papillary muscle excluded successful repair and a bileaflet $29 \mathrm{~mm}$ mechanical mitral prosthesis was implanted in the mitral position (Figure $1 \mathrm{D}$ ). Postoperative control echocardiography showed good function of the mitral prosthesis with mildly depressed LVEF. On the $10^{\text {th }}$ day after the surgery the patient was discharged from the cardiac surgical ward.

\section{Conflict of interest}

The authors declare no conflict of interest. 

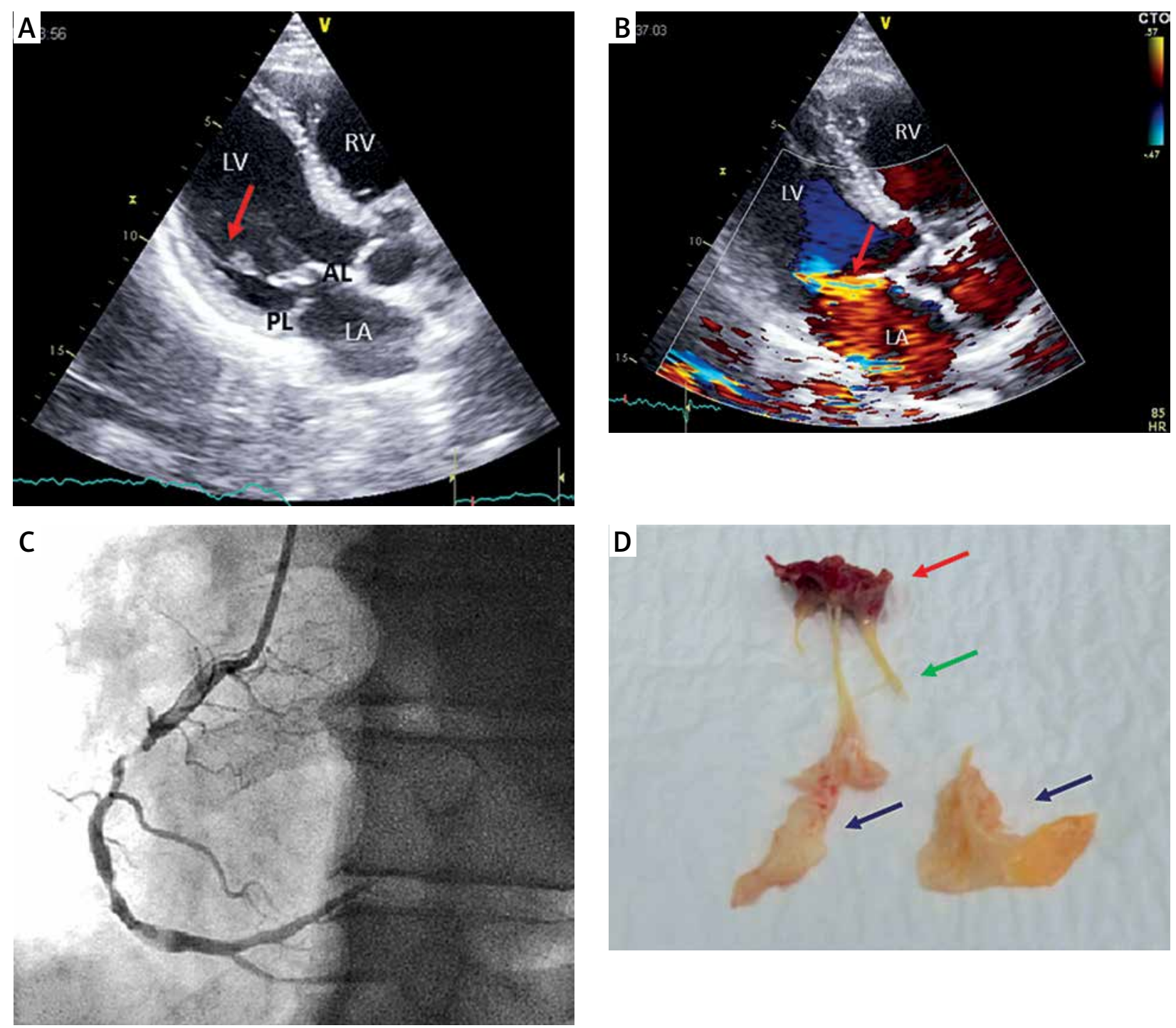

Figure 1. A - Transthoracic echocardiography, 2D grey scale - modified parasternal long axis view; red arrow indicates partial disruption of posteromedial papillary muscle resulting in partial flail of the posterior mitral leaflet. B - Transthoracic echocardiography, 2D color Doppler mode - modified parasternal long axis view; red arrow indicates eccentric jest of acute severe mitral regurgitation. C - Coronary angiography - critical stenosis of right coronary artery. D - Photography of excised mitral valve; red arrow indicates distal part of ruptured postero-medial papillary muscle, green arrow indicates chordae tendinae, blue arrows indicates residues of excised mitral valve leaflets

$L A$ - left atrium, $L V$ - left ventricle, $R V$ - right ventricle, $A L$ - anterior leaflet, $P L$ - posterior leaflet.

\section{References}

1. Kutty RS, Jones N, Moorjani N. Mechanical complications of acute myocardial infarction. Cardiol Clin 2013; 31: 519-31.

2. Jain SK, Larsen TR, Darda S, et al. A forgotten devil. Rupture of mitral valve papillary muscle. Am J Case Rep 2013; 14: 38-42.

3. Lipiec P, Uznańska B, Krzemińska-Pakuła M, et al. Acute mitral regurgitation caused by infarction-related papillary muscle rupture with successful surgical treatment: case report. Kardiol Pol 2007; 65: 1119-21. 